\title{
A new look for the Journal of Biological Physics
}

\section{Sonya Bahar ${ }^{1}$}

Published online: 16 November 2020

(C) Springer Nature B.V. 2020

Dear Readers,

I am writing to share some exciting new developments here at the Journal of Biological Physics. As you can see from the cover of the print issue, we have a new look!

The field of biological physics is growing into a mature discipline, with cutting-edge research on many different fronts. To reflect the development of the field, we are launching a new submission category, Research Letters. Letters are intended to facilitate rapid communication of cutting-edge results, complementing the longer, in-depth Original Research articles. As we launch our Letters category, we are retiring Short Notes.

In addition to launching Research Letters, we have created a set of Topical Sections, in order to more clearly identify the areas of biological physics that JOBP seeks to feature. These are:

- Biological Physics of Nucleic Acids and Proteins

- Biological Physics of Lipids and Membranes

- Big Data: Proteomics, Genomics and Lipidomics

- Biological Physics of the Cell

- Genetic Networks

- Physiology

- Neurodynamics and Neural Connectivity

- Ecology \& Evolutionary Processes

- Collective Behavior

- Other (General Biological Physics)

The sections highlight the different scales at which biological physics can be deployed to investigate interdisciplinary problems. We hope that these sections will help to better target the needs of researchers working in various branches of biological physics. New sections may be added in the future, as the needs of the biological physics community develop.

Sonya Bahar

sbahar@umsl.edu

1 Department of Physics \& Astronomy and Center for Neurodynamics, University of Missouri at St. Louis, St. Louis, MO, USA 
When you submit an article to JOBP, you will be asked to select the Topical Section that best fits your manuscript; this will enable articles to be grouped into topics across various issues of the journal, so that authors can more easily identify their areas of interest.

In addition to the changes described above, the Journal of Biological Physics will also be publishing Topical Collections. These are essentially "virtual" Special Issues on high-impact topics, bringing together articles on a common theme that may appear across several physical issues, and that will be grouped together on the journal's website.

Lastly, we plan to host virtual talks by Editorial Board members and other experts on the journal's website, as well as virtual interviews with authors whose work is published in JOBP. These will be launched in early 2021, so please follow Springer social media profiles and bookmark our website so that you do not miss any of these exciting events.

We welcome your feedback about these new initiatives and encourage you and your colleagues to submit your best work to JOBP. We look forward to your submissions, and to possibly highlighting images from your work on the journal cover!

Sonya Bahar

Editor-in-Chief

Publisher's note Springer Nature remains neutral with regard to jurisdictional claims in published maps and institutional affiliations. 